\title{
スペリー式ジャイロフィン・スタビライザー
}

\section{Sperry Gyrofin Stabilizer}

\section{山田光 雄 ‘東京計器)}

\begin{abstract}
The Sperry Gyrofin Stabilizer consists of two actively controlled underwater fins, projecting from opposite sides of the ship near its center. The fins, controlled continuously and automatically, co-operate in applying roll stabilizing moments to the ship. Stabilizing moments are ordered by the stabilization system to counteract disturbing moments applied to the ship by the wave action. For descriptive purposes, the stabilization system has two major divisions, the control system which orders the proper stabilizing moment, and the stabilizer fin machinery units which apply the ordered stabilizing moment to the ship.

The stabilizer control deduces the disturbing moment being applied to the ship from measurements of the ship's response to those disturbances. Sensing instruments detect and measure several functions of the ship's roll motion and supply the basic data needed to compute roll stabilizing moments. A computer then orders each stabilizier fin machinery unit to apply a fin lift force to the ship which will produce a stabilizing moment equal and opposite to the disturbing moment.

Although responding independently to ordered stabilizing moments, the stabilizer machinery units co-operate to apply fin angles which produce equal lift forces. Stabilizing moment applied is, therefore, in the form of a pure couple. The desirable equality of fin lift forces in the Sperry stabilizer is assured first by the equality of fin lift orders to each fin, and second by the "lift Control" feature. With lift Control, each fin servo control system compares the measured actual fin lift with the ordered lift and tilts the fin to maintain continuous equality between actual lift and ordered lift.

Two equipments of the Sperry Gyrofin Stabilizer have been installed in passengers "Mariposa" and "Montery", displacements of approximately 20,000 tons, speeds of about 20 knots, and it is reported that the sea trials were very successful.
\end{abstract}

\section{ま}

船のローリングを防ぐ方法は極めて興味ある問題として数十年以前から色及な方法が考えられ ており，我国でも約30年前に故元良博士により研究されたてとがある．従来行われて来た方法と しては,タンクによるもの，ジヤイロを用いたもの，フインを承航に張出したもの等色々な方式 がある. 
スペリージヤイロフインスタビライザーは米国スペリー会社で完成したもので，船の両舷にフ インを張出し船のローリングの状沇に応じてフインの傾斜角を自勳的に変化させて船を安走させ るもので，1956年に Oceanic Steamship Co.; の客船 Mariposa 号に，次いて1957年に同社の Montery 号に装備されている，之等は 2 万屯級の客船で，その海上試験の成績も極めて良好で あつたと報告されている.

本装置を構成している主な unit は次の通りである。

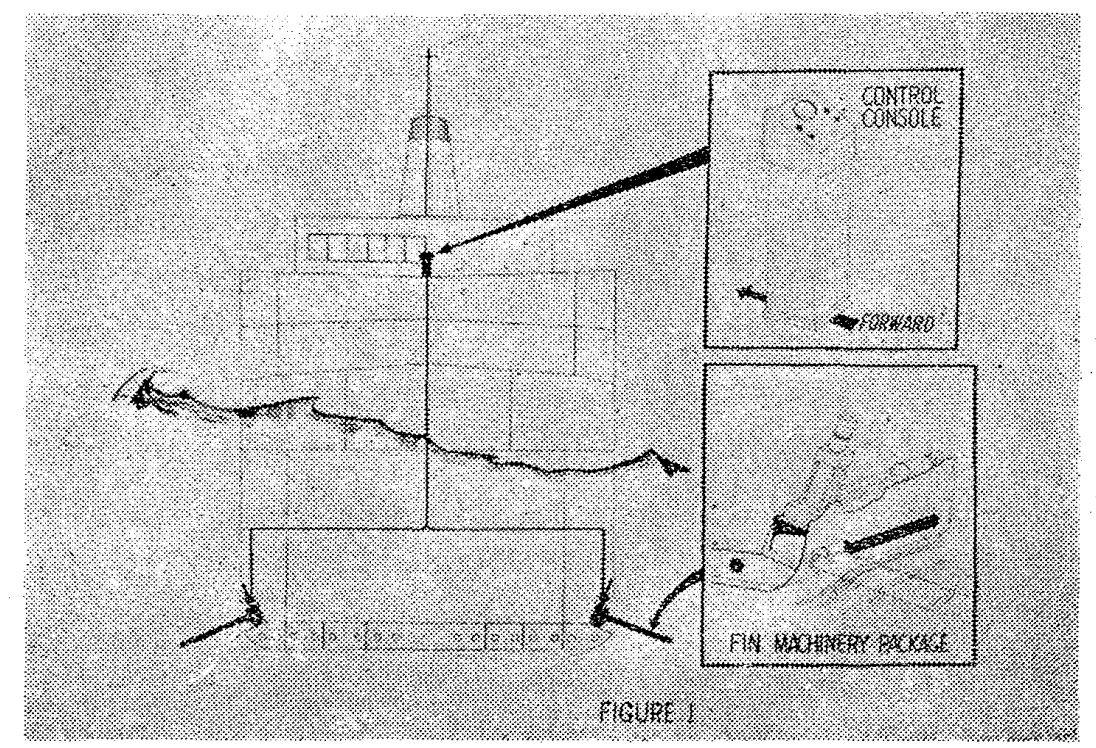

Fig 1

1. 管制器 (Control Console).

2. 機動装置 (Stabilizer Machinery unit)

3. フイン (Fin)

之等は従来のものと此べて構造が簡易で，装備容積が小さく，重量が軽減されている。

機能

本装置の制御系統を Fig 4 亿示す。

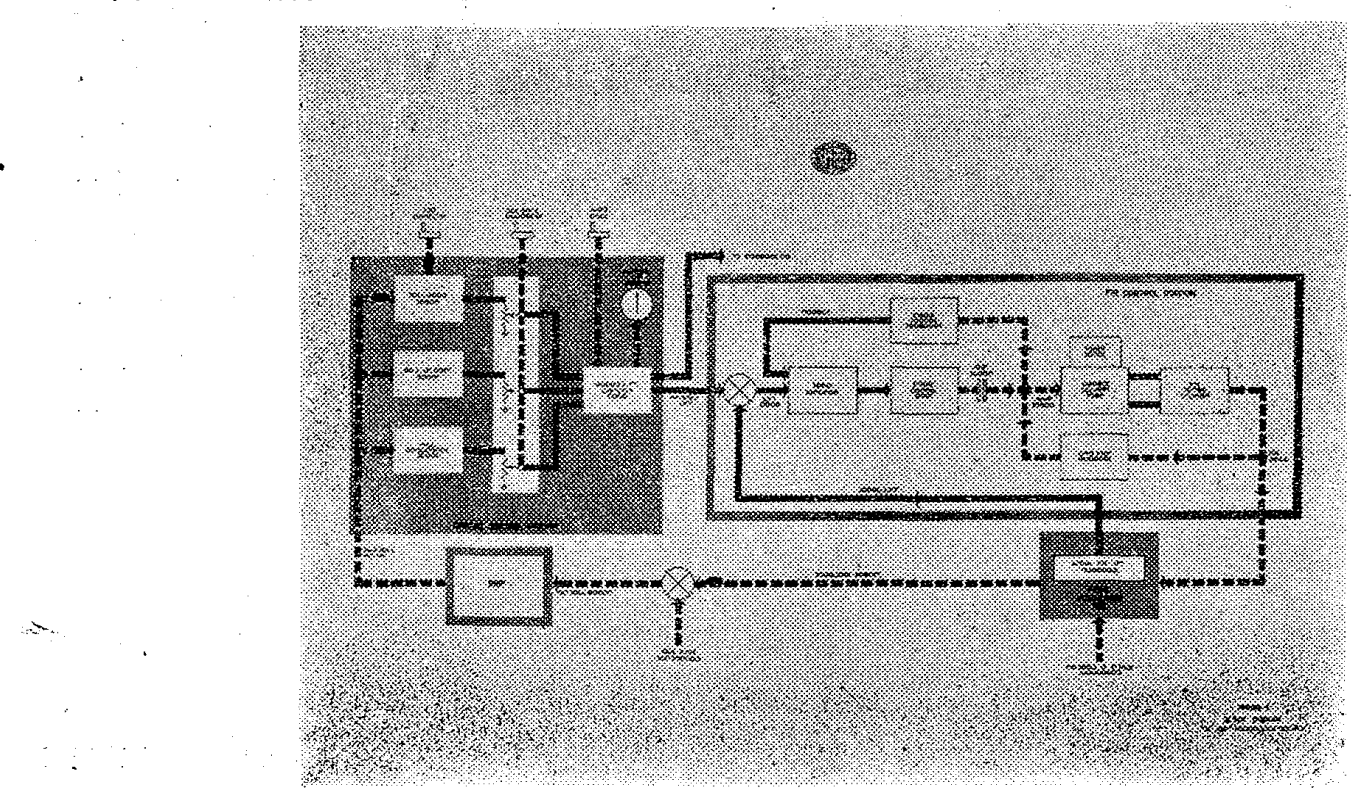

Fig 4 
操舵室に装備した管制器はローリングの角度，角速度及び角加速度をジヤイロその他によつて 検出し之等の信号をコンピンーターに入れて船を安定させるに必要なモーメントを即ちフインに 働くべき揚力を計算し，フインの傾斜角を決定して機動装置に命令を出す.

機動装置はフインの傾斜角の変更, フインの張出し, 格納を行う装置で, 夫љの作動は油圧シ リンダーによつて行われる。管制器からの命令に従つて油圧回路を制御し，フイン傾斜シリンダ 一のピストンストロークを決定してフインを所要角度だけ傾斜させるのである.両䑨のフインは 夫及反対方向の力を受ける様に動くので船体には安定モーメントが衝いて波浪の影響に打勝つて ローリングを減少させるのである。

本装置の最も大きな特長は揚力制御 (Lift Control) である.之はフインが海水から実際に受 ける揚力を測定して之を管制器から命命された揚力と此較し，その間に美異があれば更にフイン の傾斜危を修正する方法で、との方式の採用汒よつてスタビライザーの性能が大きく改善された のである.

\section{管 制 器}

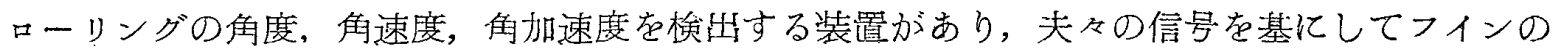
揚力を計算するコンピユーターを持つている．上面の Panel には速度調整(Speed Adjustment) 天候調整 (Sea State Adjustment) 及び船体傾斜角修正 (List Correction) の装置がある. 叉 船の速度が或程度以下に落ちるとフインの効率が憲くなるので，このための警報装置 (Low Speed Alarm) 肪ある. この外各フインの傾斜危を示す指示器や，フインの張出，格納を行う スイツチがある。

機動装置とフイン Fig 1, Fig 2.

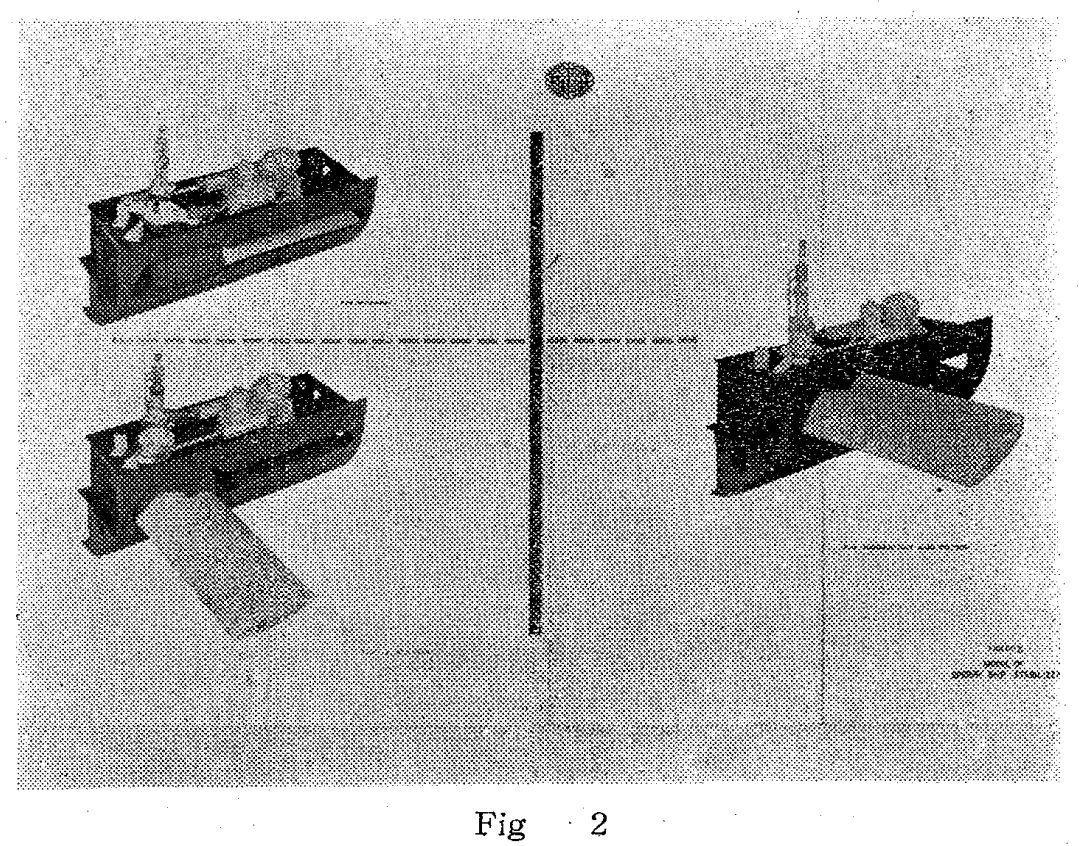

機動装置はフインの張出，格納及びフインの傾斜を与光る動力装置で，作動はすべて油圧によ つて行うので油压ポンプ装置を備えている.

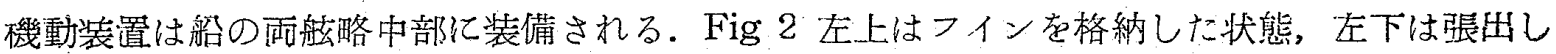
たところ，フインが傾斜した状態である。 


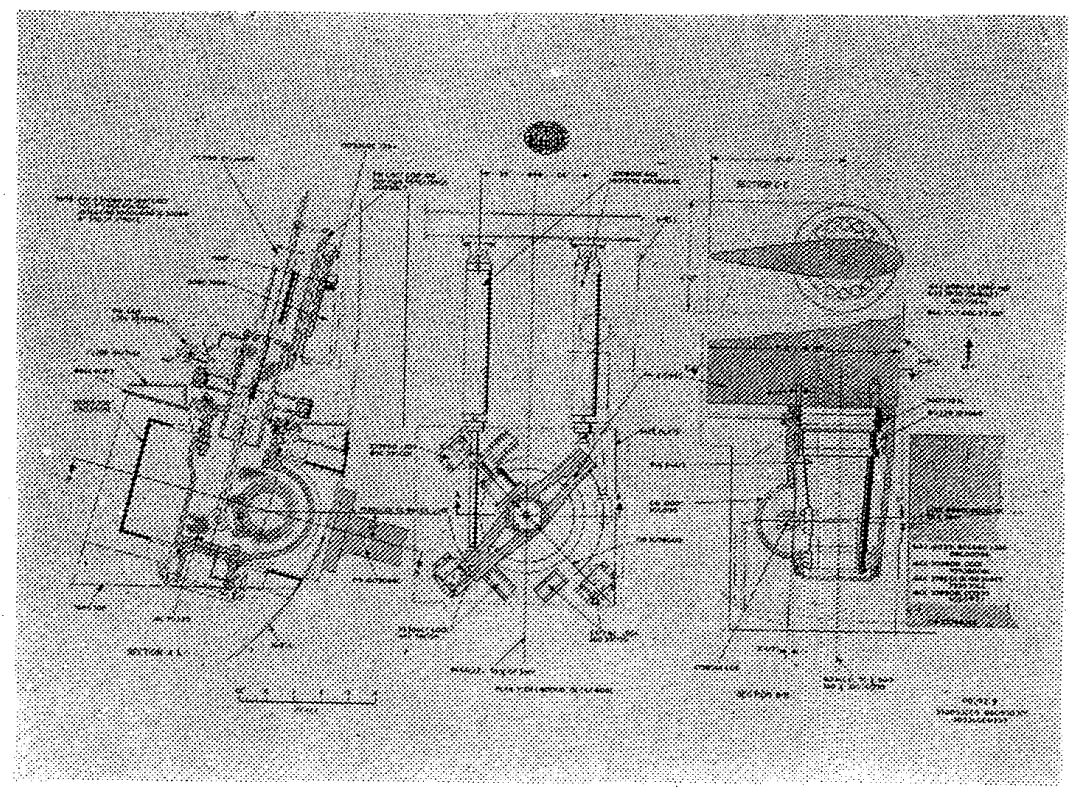

Fig 3

Fig 3 亿機動部の詳細を示す.Fig 3 中央の図によりフインの脹出, 格納は 2 個の油圧シリン ダーによつて行われることが解る，図はフイン格納の状態であり，格納，張出夫ふ位置に固定装 置がある．左図は格納㨼出の回転軸の断面を示するので軸は中空で上下の軸で支持されている. 軸の上部にはフイン傾斜シンリンダーがありピストンの上下運動によりフインシャフトを回転さ せフインの傾斜を変える様になつている. 右図はフインシャフトの状態を示す．フインシャフト は中空の円錐形で両端の 2 個の軸受で格納張出朝内に支持されている.フインシャフトの太い方 の端にはフインが取付けられている. 図はフイン格納の状態を示す。

フインの断面は流線型で効率を良くするため後側に簡単なりンクで作動するフラップがある. フインシャフトの中にはトランスデニーサーがあつて, フインにかかる揚力によつてフインシャ フトに歪を生じたとき此の変位によつて揚力を実測し揚力制御を行い得る様になつている.

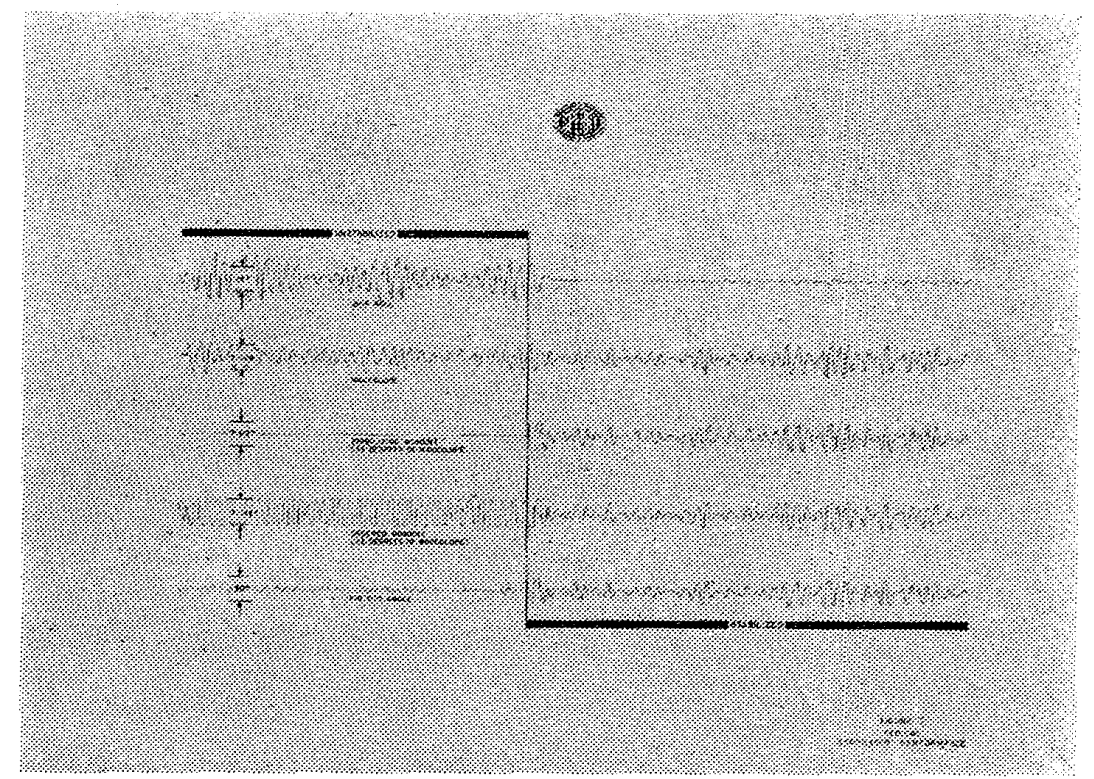

Fig 5 
性能

1. 船の噸数 2 万电

2. 速力 20 ハット

3. メタセンター $3 \sim 4$ フイート

4. 機動装置 2 基

長さ約 25 フイート，幅 9 フイート，高さ14フイート，重さ 1 基当り約53屯

5. フイン最大傾斜角 士25度

6. フインの傾斜速度 最大 30 度/秒

7. フインの揚力 フイン傾斜 20 度, 速力 20 ハットのとき揚力70屯

8. 油圧ポンプ電動機 1 台当り $75 \mathrm{P}$

9. Fig 5 は試験成績の一例である.

\section{む す び}

前記 Mariposa 号及び Montery 号に於ける海上試験では色ぬな速力，色々な天候に対して 実験が行われ優れた性能が実証されている。

Moriposa 号がホノルル沖で同型船 Matson C-3 号と同行したが， Matson 号のローリング が 25 度のとき Mariposa 号は 3 度で平常と何等変らなかつた由である. 之等の成績は限られた 期間中の海上試験の結果であるが，今後長期間にわたる実用試験の成績を期待するるのである. 